\title{
Lésbicas = 'Afeto' / Gays = 'Sexo'?: Discutindo Práticas Homoconjugais no Seriado Queer as Folk.
}

\author{
Lesbians = 'Affection' $/$ Gays = 'Sex'?: Discussing Homo Marital Practices in the \\ Series Queer as folk.
}

\author{
Ramon Pereira dos Reis \\ Universidade Federal do Pará \\ rpreis18@yahoo.com.br
}

\section{Resumo}

Este artigo se propõe a compreender como se estabelecem as práticas homoconjugais expostas no seriado americano Queer as Folk, enfatizando o papel da mídia e da cultura. A cultura, nesse sentido, é significativa para pensarmos a simbólica estruturante dos pares homossexuais: a maneira de se vestirem, de falarem, de estabelecerem relacionamentos; a mídia, então, repassa aquilo que visualiza de maneira dramática ou não.

Palavras-chave: Práticas Homoconjugais; Cultura; Mídia; Queer as Folk.

\begin{abstract}
This paper aims to understand how the homo marital practices are established in the American series Queer as Folk, emphasizing the role of media and culture. The culture in this sense is meaningful for the symbolic structuring of homosexual couples: the way they dress, talk and establish relationships. The media then, shows what it sees in a dramatic way or not.
\end{abstract}

Keywords: Homo marital practices; Culture; Media; Queer as Folk. 


\section{Introdução - Conhecendo o Seriado Queer as Folk (Os assumidos) ${ }^{1}$.}

Queer as Folk é o nome de duas séries televisivas, enquadradas no gênero drama, ambas criadas por Russell T. Davies. A série original começou a ser produzida em 1999, pela Red Production Company para o canal aberto, Canal 4, do Reino Unido. Expunha o cotidiano de três homens gays vivendo em Manchester.

Posteriormente, o seriado foi adaptado, por Ron Cowen e Daniel Lipman, ${ }^{2}$ em uma coprodução: Estados Unidos Canadá e começou a ser transmitido em 2000, nos seguintes canais de televisão a cabo: Showtime (EUA) e Showcase (Canadá), vale ressaltar que os 13 primeiros episódios seguiram autênticos à concepção original. Tendo como protagonistas cinco homens gays e um casal de lésbicas que viviam em Pittsburgh, Pensilvânia. ${ }^{3}$

Houve algumas diferenças entre os dois seriados: ${ }^{4}$ primeiro, na quantidade de personagens e tramas principais, pois na versão inglesa apareciam apenas três personagens masculinos gays (protagonistas) e, por conta do menor número de atores as relações que se estabeleciam eram de densidade menor, se comparadas à versão americana, onde todos os acontecimentos envolviam um número maior de pessoas e isso fazia com que o seriado se tornasse, de certa forma, mais envolvente.

Um segundo aspecto: a versão americana teve um total de cinco temporadas e a britânica, somente duas ${ }^{5}$, talvez esse seja um dos fatores pelo qual a versão americana tenha obtido mais sucesso ${ }^{6}$ do que a versão inglesa, sendo que ambas não se preocuparam em exibir cenas de nudez e sexo. Minha análise irá focar na versão americana deste seriado, especificamente na $1^{\text {a }}$ temporada, composta por 22 episódios.

No Brasil, o seriado estreou em 2001, sendo transmitido pelo canal pago, Cinemax. Até hoje, os DVDs da série não foram lançados no Brasil, estando apenas disponível na internet para quem queira baixar os episódios ou para aqueles que pretendem comprálos.

A versão norte-americana de Queer as Folk (QAF) ${ }^{7}$ tem como ambientação a cidade de Pittsburgh Pensilvânia, dando ênfase e colocando em primeiro plano, a boate Babylon, voltada ao público $\mathrm{GLS}^{8}$ (gays, lésbicas e simpatizantes), sendo caracterizada num lugar que toca música eletrônica, possui dançarinos no estilo go go boys, dark room, bebidas e drogas. Habitando juntamente nesse espaço, está presente o grupo de amigos: Brian, Michael, Justin, Emmett e Ted. Além da boate, tal grupo costuma frequentar o bar Woody's, onde eles se reúnem para beber, fumar, flertar, conversar e outro espaço de convivência é o restaurantelanchonete Liberty Diner, local onde trabalha a mãe do personagem Michael (Debbie) e o garoto Justin, há também uma academia, onde Brian, Michael, Ted e Emmett costumam frequentar. Tais espaços se configuram como elos de sociabilidade 9 , pois é lá que ocorrem as relações sexuais, os encontros, os acontecimentos divertidos, as tensões, os romances, etc. Além disso, esses lugares estão imbricados um ao outro, pois mantém conexão entre si e estão localizados na mesma avenida, Liberty Avenue (Avenida Liberdade). ${ }^{10}$

Além do grupo de amigos, ainda estão presentes na primeira temporada, o casal de lésbicas (Lindsay e Melanie), a amiga de Justin (Daphne), o tio de Michael (Vic), a mãe de Michael (Debbie), a mãe de Justin (Jennifer) e o namorado de Michael (David).

QAF não dialoga com discursos que colocam a homossexualidade em campos periféricos de debate, mostrando o universo LGBT $^{11}$ (Lésbicas, Gays, Bissexuais, Travestis e Transexuais) sem encobrimentos das questões que dizem respeito ao amor, aos formatos de família, aos relacionamentos, etc., e, nem tampouco encobre o fato das personagens serem gays ou lésbicas. ${ }^{12}$

A importância deste seriado para o público em geral, está no fato de que, apesar de ser uma série voltada ao público LGBT, ela se vale para mostrar como é construído o espaço de convivência dessas identidades e, também, serve como modelo de identificação, daquilo que chamaríamos de "ser gay" e "ser lésbica". As construções estereotipadas, tais como: branco / classe média alta / heterossexual, são reformuladas e resignificadas a partir das relações homossexuais ${ }^{13}$, todavia reforça padrões de gênero que se assemelham aqueles esperados das relações heteronormativas. Tais aspectos serão trabalhados mais

\section{Ramon Pereira dos Reis}


adiante. Vale ressaltar, que nós não devemos excluir a identidade, se é pelo viés desta identidade que as pessoas encontram seu prazer, mas não devemos considerar essa identidade como uma regra ética universal (FOUCAULT, 1982, p. 4). Podemos pensar, a partir dessa lógica, que a construção da identidade pode ser reformulada e transformada, visto que as construções das relações existentes são estereotipadas, portanto, passíveis de modificação, ou seja, a identidade é realmente algo formado, ao longo do tempo, através de processos inconscientes e, não algo inato, existente na consciência no momento do nascimento (HALL, 2006, p. 38).

\section{Conjugalidades Homossexuais}

Adentrando na especificidade deste trabalho, o seriado QAF representa a conjugalidade homossexual (prática homoconjugal), por um casal de lésbicas (Melanie e Lindsay) que possuem um filho (Gus), pelo casal de gays (Michael e David) e também por outro casal de gays (Brian e Justin). Entende-se aqui, que a conjugalidade:

(...) não é aquela que emerge de um fato jurídico. É, isto sim, o que expressa uma relação social que condensa um 'estilo de vida', fundado em uma dependência mútua e em uma dada modalidade de arranjo cotidiano, mais do que propriamente doméstico, considerando-se que a coabitação não é regra necessária (HEILBORN, 2004, p. 11 - 12).

Tais relações são estabelecidas, no caso das mulheres: a personagem Lindsay, que irá gestar o bebê (Gus) para de trabalhar como Professora de Arte, para se dedicar exclusivamente à criança, enquanto que a sua parceira (Melanie), continua sua vida normal, trabalhando como Advogada e garantido o sustento da família. No caso dos homens, o casal que se forma a partir do $5^{\circ}$ episódio (Michael e David), estabelece sua relação da seguinte forma: Michael é Supervisor em uma loja de departamentos (Big Q) e não garante as despesas da casa, por outro lado, David que é Fisioterapeuta, tem uma vida independente financeiramente ficando encarregado de bancar os custos mensais da casa. O outro casal: Brian e Justin, a princípio, com uma relação bastante conturbada, são percebidos de maneira que, Brian, Publicitário de sucesso, independente financeiramente, arca com as despesas de Justin, que ainda estuda no colegial e é "dependente" de Brian.

De forma analítica, com relação ao casal de lésbicas, uma das mulheres carrega consigo características estereotipadas, conhecidas pelo senso comum com 'femininas' - ser compreensível, doce e frágil -, num viés diferente, a outra mulher do casal, desempenha um papel "masculinizado" - é forte, independente e trabalha fora, ou seja, garante todo o sustento da família. Nesse sentido, podemos dizer que o seriado reproduz certa lógica de gênero, onde a família torna-se o local da 'feminilidade', e a rua, o trabalho, espaço para a 'masculinidade'14 (DAMATTA, 1997 [1936]; FRY \& MACRAE, 1991).

Passando para os casais masculinos, as relações que se estabelecem, são sempre mostradas como relações descompromissadas e que, mesmo quando um casal se forma, como é o caso dos personagens de David e Michael, os comportamentos são de um casal que quer ter uma vida livre: poder sair com os amigos, serem vistos pelos outros, serem desejados por outras pessoas. Isso pode ser percebido em um dos diálogos entre David e Michael, no $18^{\circ}$ episódio, quando o personagem Michael descobre que David foi à sauna:

\section{David: 'Eu fui à sauna'}

Michael: 'O que foi fazer lá?'

David: 'Apenas dar uma volta. Ouça! Não é

algo que faço sempre, Michael! É a primeira vez desde que estamos juntos'

Michael: 'Não quero falar disso!'

David: 'Não, você deve saber!'

Michael: 'O quê? Que você transa por aí?'

David: 'Eu não transei'

Michael: 'E depois você vem pra casa transar comigo. Se me transmitiu algo...'

David: 'Não, eu disse que não transei!... Eu apenas me masturbo'

Michael: 'Apenas. Eu não entendo. Não sou suficiente pra você?'

David: 'Sim, claro que é! Michael'

Michael: 'Então, por que fez isso?'

David: 'Eu não sei... Acho que foi pela excitação... Quero que os caras me achem atraente. Não sei, às vezes... preciso sair sozinho'

Michael: 'Você é um mentiroso!'

David: 'É a verdade. Michael'

Michael: 'Dane-se! Você e a sua verdade'

Deste modo, a figura do homem é colocada enquanto ser que está propenso ao sexo, de forma natural e supostamente incansável. A trama envolve o telespectador, a partir da exacerbação da figura do homem, centrando-o no discurso e na imagem. É importante atentar para o caráter puramente volátil das relações homoconjugais entre homens: o

\section{Ramon Pereira dos Reis}


relacionamento entre tais sujeitos se faz presente em apenas um curto período de tempo, não sendo necessário estabelecer um vínculo mais duradouro. $\mathrm{O}$ prazer de estar com a pessoa acaba logo após o ápice do sexo. Isso fica explícito no diálogo entre Brian e Justin, no $2^{\circ}$ episódio:

\section{Justin: 'Você não namora ninguém' \\ Brian: 'Mikey andou conversando com você' Justin: 'Você transa com todo mundo. Ele é feio. Você nem conhece ele. E eu? Eu realmente...' \\ Brian: 'Eu transei com você. $O$ que aconteceu na noite passada foi apenas uma diversão. Eu queria você e você me queria. Foi tudo o que aconteceu' \\ Justin: 'Uma transa?' \\ Brian: 'O que pensava que tinha sido? Olha! Eu não acredito no amor. Eu acredito em sexo. É honesto. É eficiente. Você sai com o máximo de prazer e o mínimo de compromisso. Amor é uma coisa que os héteros dizem que existe, só pra terem uma razão pra transar e depois acabam machucando um ao outro. Porque foi tudo baseado em mentiras pra começar. Se é isso que você quer, então vá e encontre uma linda garotinha! E case-se com ela!' \\ Justin: 'Não é isso que eu quero. Eu quero você!' \\ Brian: 'Você não pode me ter. Estou muito velho. Você é muito jovem pra mim. Você tem 17. Eu tenho 28' \\ Justin: '29' \\ Brian: 'Tudo bem. 29. Mais um motivo. Agora vai fazer a sua lição de casa'}

Vale ressaltar, que não podemos generalizar e dizer que todos os casais homossexuais masculinos e homossexuais femininos se comportam da mesma forma ${ }^{15}$, visto que não existe um único estereótipo da homossexualidade na mídia. Dessa forma, identidades corporais podem se conformar ou não às regras de gênero e sexuais, esta, apontam para a tríade heterossexual: ${ }^{16}$ sexo - gênero - sexualidade, ou seja, o indivíduo nasce com um sexo determinado, em seguida compõe sua identidade de gênero a partir de seu órgão genital e, mais adiante, engloba em seu arcabouço corpóreo a maneira como irá expor seus prazeres e desejos com o sexo oposto.

Para a maioria da população, em geral, condicionada ao pensamento heterossexista, as afirmações, expostas acima, são polêmicas e provocadoras, pois fogem à regra do que para as convenções sociais deve ser determinante: pênis masculino - heterossexual - relacionamento afetivosexual com mulheres / vagina - feminino heterossexual - relacionamento afetivo-sexual com homens.

A partir das produções acadêmicas voltadas para uma perspectiva de gênero, bem como, mais recentemente, com a Teoria Queer ${ }^{17}$, podemos dizer que tais padrões homoconjugais: homem - ativo trabalha fora de casa / mulher - passiva - dona de casa, podem ser colocados em xeque no seriado, visto que, nem todos os homens são ativos e trabalham no espaço público e, nem todas as mulheres possuem relação de passividade e são donas de casa.

O binarismo masculino / feminino se faz presente no entorno das relações polares entre 'ativo' e 'passivo'18, não se limitando apenas ao ato sexual, assim como na interação entre 'papéis sexuais', onde o 'falo' representa a discussão central nas relações. Podemos exemplificar essa lógica a partir deste esquema: penetrador $=$ dominante $/$ penetrado $=$ dominado. O fato é, portanto, que, 'atividade' significa poder em relação à 'passividade', que faz com que as relações de poder da vida cotidiana possam ser, algumas vezes, invertidas, temporariamente, no ato sexual de coito anal (FRY \& MACRAE, 1991, p. 51).

Esta imagem, que se torna recorrente na série, é transposta às personagens tidas como 'passivas' que são representadas enquanto dependentes financeiramente e, estão localizadas num ambiente privado, como por exemplo: Brian e Justin: Brian é publicitário, desempenha o papel de ativo na relação e é independente financeiramente / Justin é estudante do colegial, desempenha o papel de passivo na relação e é dependente dos pais; David e Michael: David é fisioterapeuta, desempenha o papel de ativo na relação e é independente financeiramente / Michael é supervisor em uma loja de departamentos (Big Q), desempenha o papel de passivo e é 'dependente' financeiramente de David; Melanie e Lindsay: Melanie é advogada, desempenha o papel de ativo na relação, é aquela que trabalha fora para garantir o sustento da família / Lindsay é professora de arte, desempenha o papel de passivo e é dependente de Melanie.

Considera-se, que as relações identitárias lineares, tais como: lésbicas / família / estabilidade conjugal / maternidade / afetividade e, gays / corpos / sexo / relações voláteis / espaço público, se constituem enquanto estereótipos que reafirmam e rearticulam a lógica heterossexual. Tomamos como base, o que Goffman (2008) diz acerca do conceito estigma:

(...) o estigma envolve não tanto um conjunto de indivíduos concretos que

\section{Ramon Pereira dos Reis}


podem ser divididos em duas pilhas, a de estigmatizados e a de normais, quanto um processo social de dois papéis no qual cada indivíduo participa de ambos, pelo menos em algumas conexões e em algumas fases da vida. O normal e o estigmatizado não são pessoas, e sim perspectivas que são geradas em situações sociais durante os contatos mistos, em virtude de normas não cumpridas que provavelmente atuam sobre o encontro. Os atributos duradouros de um indivíduo em particular podem convertê-lo em alguém que é escalado para representar um determinado tipo de papel; ele pode ter de desempenhar o papel de estigmatizado em quase todas as situações sociais, tornando natural a referência a ele, como eu o fiz, como uma pessoa estigmatizada cuja situação de vida o coloca em oposição aos normais. Entretanto, os seus atributos estigmatizadores específicos não determinam a natureza dos dois papéis, o normal e o estigmatizado, mas simplesmente a frequência com que ele desempenha cada um deles. E já que aquilo que está envolvido são os papéis em interação e não os indivíduos concretos, não deveria causar surpresa o fato de que, em muitos casos, aquele que é estigmatizado num determinado aspecto exibe todos os preconceitos normais contra os que são estigmatizados em outro aspecto (GOFFMAN, 2008, p. 148-149).

Diante de tais colocações, o seriado em questão, se articula a partir de uma lógica predominante, a heterossexista, apesar de conseguirmos visualizar que este é um produto midiático, voltado a um público específico, o determinante heterocentrista ainda é muito forte, por exemplo: colocação das personagens lésbicas em segundo plano, o ativo ser superior ao passivo, enfatizar os relacionamentos homossexuais masculinos ao invés de colocá-los em pontos de igualdade com os femininos.

\section{Lésbicas = 'Afeto' / Gays = 'Sexo'?}

As explanações, a seguir, trazem à baila a discussão que se faz sobre as práticas homoconjugais, explorando não apenas a maneira como tais casais são representados no seriado, assim como fazendo relação com a pesquisa de campo, no sentido de utilizá-la como ferramenta que nos ajuda a entender, um pouco mais, sobre a nossa realidade.
Procuro, enquanto objetivo geral, compreender como se estabelecem as relações homo-masculinos e homo-femininos no seriado em questão. Parafraseando (PAIVA, 2007, p. 341): o foco analítico do trabalho recaiu sobre o 'artesanato' dessas relações revelando a dimensão da sociabilidade do dia a dia, das micro redes relacionais, da economia dos sentimentos. Acredito que diversos são os fatores para se tentar entender como se estabelecem tais práticas homoconjugais. Na maioria dos casos, convencionouse culturalmente em dizer que existem identidades de gênero que já estão determinadas desde o nosso nascimento, ou seja, na nossa sociedade, é comum ouvirmos da maioria das pessoas, que: mulher é mais afetuosa, mais romântica, enquanto que o homem é mais sexo e menos romântico ${ }^{19}$. Seguindo essa lógica, podemos dizer que:

A socialização de gênero na nossa cultura ensina os homens a serem mais interessados em sexo e em variedade sexual do que as mulheres. Por outro lado, para muitas mulheres, independente de sua orientação sexual, sexo e amor estão intimamente ligados, o que faz com que relações casuais sejam menos atraentes (NUNAN, 2007, p. 59)

Tais construções convencionais de gênero podem ser percebidas no seriado, pois numa análise rápida e com poucas elucubrações teóricas, é perceptível a existência de diferenças entre homens e mulheres homossexuais, tanto nas relações sexuais como nas sociais. O casal de lésbicas é mostrado desde o início da série, como um casal que já está firmado: as duas têm um filho, são mostradas enquanto personagens que se restringem ao ambiente da casa, e, apesar das discussões, na maioria das cenas aparecem demonstrando carinho uma pela outra. No caso dos homens: são, constantemente, mostrados com os amigos, na boate, no bar, não possuem relações fixas com os parceiros e, se contentam, muito mais, com o prazer sexual.

A princípio, quando assistimos pela primeira vez QAF, não nos damos conta que apesar de existirem modelos conjugais, que destoam, aparentemente, de padrões heterossexuais (homem e mulher), no entanto, no momento dos pares estarem juntos numa casa, num apartamento, por exemplo, ocorrem situações semelhantes à de um casal heterossexual, ou seja, no caso das personagens lésbicas do seriado (Lindsay e Melanie), ao manterem conjugalidade, elas estabelecem papéis identitários de gênero: Lindsay dona de casa - mãe - 'dependente' financeiramente de

\section{Ramon Pereira dos Reis}


sua parceira / Melanie - trabalha fora - se considera o "pai” na relação - paga as contas. No lado masculino, podemos mencionar dois casais: Justin - dependente dos pais - mora inicialmente com a família e depois vai morar com amigos - nas práticas sexuais se comporta como 'passivo' / Brian - Publicitário - mora sozinho - nas práticas sexuais se comporta como 'ativo'; O outro casal: Michael - 'dependente' financeiramente de David - se comporta como 'passivo' / David - Médico - mora sozinho - se comporta como 'ativo' 20 .

Apesar de Heilborn (2004); Nunan (2007) destacarem que: no par homossexual é abolida a classificação do gênero, prevalecendo à expectativa de independência econômica entre os parceiros, percebemos, no seriado, uma diferenciação no sentido do ser independente tanto financeiramente quanto sexual, ou seja, a série não coaduna com o pensamento das autoras acima, estabelecendo hierarquias entre os sujeitos masculinos e femininos. As discussões, no seriado, giram em torno da questão do 'falo', onde quem o possui ocupa a posição de dominador e o que não o possui é dominado. No caso feminino, há uma pequena diferença: o discurso das mulheres não registra a vigência de uma gramática da cópula ${ }^{21}$ nos termos 'passividade / atividade', como ocorre entre os homens gays (HEILBORN, 2004, p.180). Mas, ainda assim, o seriado estabelece padrões hierárquicos, tanto para gays quanto para lésbicas, não dizendo respeito apenas ao âmbito sexual, bem como ao financeiro.

Dentro dessa homocorporalidade, ${ }^{22}$ podemos destacar questões que dizem respeito ao âmbito da casa e da rua, enquanto categorias de análise que nos ajudam a entender uma possível lógica da construção das relações entre gays e lésbicas, pelo fato de que as personagens 'passivas' são constantemente representadas enquanto "dependentes" na questão financeira e ligadas ao âmbito privado (casa). Para DaMatta (1997) 'casa' e 'rua':

(...) são categorias sociológicas para os brasileiros, estas palavras não designam simplesmente espaços geográficos ou coisas físicas comensuráveis, mas acima de tudo entidades morais, esferas de ação social, províncias éticas dotadas de positividade, domínios culturais institucionalizados e, por causa disso, capazes de despertar emoções, reações, leis, orações, músicas e imagens esteticamente emolduradas e inspiradas (DAMATTA, 1997, p. 15).

Nesse sentido, associar as lésbicas ao ambiente da casa e os gays ao ambiente da rua, se constituem enquanto domínios culturais institucionalizados que no Brasil, bem como, no seriado são fortemente marcados, mas isso não quer dizer que tais categorias ocupam uma posição estática e absoluta, pelo contrário, há uma movimentação dos sujeitos no espaço urbano, rua e casa se reproduzem mutuamente, pois existem espaços na rua que podem ser fechados ou apropriados por um grupo, categoria social ou pessoas, tornando-se sua 'casa', ou seu 'ponto' (DAMATTA, 1997). Apesar de haverem diferenças econômicas, culturais, sociais, entre os Estados Unidos e o Brasil, no momento em que visualizamos algumas cenas, percebemos que os padrões de gênero (masculinos e femininos) são parecidos aos do Brasil, ou seja, as personagens femininas (heterossexuais e homossexuais) são, na maioria das vezes, representadas desenvolvendo atividades ligadas ao âmbito do privado, da casa; no caso dos personagens masculinos, tais sujeitos se movimentam no espaço urbano e, de certa forma, podemos associar essas práticas às considerações feitas por Roberto DaMatta.

No percurso de QAF, o único casal de lésbicas que é representado, aparece como um modelo de conjugalidade convencional (heterossexual) e, tal qual nesse modelo, decidem ter um filho. Brian, então, teria sido escolhido por ser amigo de Lindsay desde a época da faculdade. Logo no primeiro episódio, percebemos a inserção das personagens lésbicas na trama, através da maternidade. ${ }^{23}$

Ao representar o casal de lésbicas, o seriado recorre, inicialmente, ao estereótipo mais recorrente ao universo feminino, que é a relação intrínseca da mulher com a maternidade. Segundo ZANFORLIN (Apud HALL, 1997), o estereótipo reduz, exagera, simplifica, essencializa, naturaliza e fixa a diferença, demarcando fronteiras de fácil e reducionista identificação. Dessa forma, a construção estereotípica $^{24}$ além de funcionar como marcador de identidades, é uma forma de excluir os indivíduos, que não se enquadram em um determinado perfil e / ou padrão.

Fry \& MacRae (1991), em um dos estudos clássicos sobre homossexualidade, destacaram que no Brasil os papéis sexuais são rigidamente separados:

Desde a mais tenra infância, meninos e meninas são educados para se portarem como homens e mulheres mais tarde. Os homens deveriam ser fortes, trabalhadores capazes de sustentar sua família, interessados em futebol e outras atividades definidas como masculinas e, sobretudo, não deveriam chorar... As mulheres, por outro lado, aprendem as tarefas de casa e

\section{Ramon Pereira dos Reis}


lhes é imbuído o que se chama de instinto materno. Ao contrário dos homens, não podem ter relações sexuais antes de casar, chegando ao casamento ainda virgens. Além disso, ainda neste Brasil popular, uma vez casadas, não deveriam demonstrar muito gosto pelo sexo (FRY \& MACRAE, 1991, p. 41-42).

Dentro da perspectiva dos autores, destacados acima, temos uma noção de que as percepções identificadoras dos gêneros masculinos e femininos, tais como: mulher - carinhosa - ambiente da casa e homem - sexo - ambiente da rua, são concepções embasadas pela cultura, pelos significados apreendidos de educação, comportamento, etc.

Especificamente, ao falarmos de gays e de lésbicas, percebemos que existe um universo que possui características específicas, tanto nas práticas sexuais, quanto nas sociais, com relação a essa questão, novamente Fry \& MacRae (1991) puderam constatar, numa pesquisa feita com homossexuais masculinos e femininos em São Francisco, que os homens tendem a ter relações sexuais muito mais frequentes que as mulheres.

De forma menos objetiva, qualquer frequentador do meio lésbico pode chegar à mesma conclusão, pois é comum se encontrar casais de mulheres que, apesar de se considerarem um par ou um "caso", mantém pouquíssimas relações sexuais uma com a outra. Muitas vezes, é o vínculo afetivo que é considerado mais importante, ou então o contato sexual pode ser mais uma questão de carícias feitas em várias regiões do corpo do que um contato voltado essencialmente para os órgãos genitais. Outro dado constatado é que, embora haja uma tendência para os homossexuais de ambos os sexos serem mais promíscuos que seus equivalentes heterossexuais, no geral as lésbicas têm "casos" mais duradouros que homens, além de serem mais "fiéis" às suas parceiras do que eles. Recentemente, tem até sido difundida a posição de que as sexualidades masculina e feminina seriam intrinsecamente diferente, tanto as mulheres heterossexuais quanto as homossexuais dariam muito menos ênfase à genitalidade que os homens, sendo mais adequado considerar a sua sexualidade como difusa em seu corpo inteiro e muito menos centrada na experiência de um clímax cujo modelo geralmente é a ejaculação masculina. Isto serviria para explicar as grandes diferenças geralmente encontráveis no comportamento sexual de homossexuais de ambos os sexos (FRY \& MACRAE, 1991, p. 106-107).

A partir deste subitem, podemos vislumbrar possíveis considerações a respeito das determinações identitárias dos papéis sexuais masculinos e femininos, que envolvem práticas sexuais assim como sociais. Sem a intenção de esgotá-las aqui, espero que seja propiciadora de reflexões e compreensões acerca de tais convenções culturais.

\section{Como as Personagens Lésbicas e Gays, do Seriado, Encaram as Relações Homoconjugais?}

Neste subitem, começarei minha explanação mostrando alguns diálogos entre as personagens gays e as personagens lésbicas e, em seguida, farei as análises. No diálogo, a seguir, Brian e Michael conversam (ambos falam sobre o encontro de Michael com David):

Michael: É estranho ter um encontro.

Brian: Deixe que abra a porta do carro $e$ puxe a cadeira pra você.

Michael: Me refiro a isso. É tão... Hétero! Já esteve em um encontro de verdade?

Brian: Uma vez. Terminei "trepando" com o garçom.

Michael: Eu não sei o que fazer ou o que dizer.

Brian: Seja você mesmo!

Michael: Isso fará a noite voar. Porque não podemos ir direto pro sexo?

Brian: O motivo de um encontro, ou como me foi explicado, por aqueles que costumam fazer isso, é conhecer bem a outra pessoa antes de "trepar" com ela.

Michael: Que ideia idiota! E se não gostar dele?

O próximo diálogo, será do casal de lésbicas (Lindsay e Melanie), na ocasião da cena, elas conversam com Justin sobre o fato da personagem Daphne (colega de escola de Justin) estar 'apaixonada' por ele, pois Justin e Daphne tinham transado, sendo que foi a primeira vez que Justin se envolveu, sexualmente, com uma garota e, era a primeira relação sexual de Daphne: 
infidelidades (HEILBORN, 2004, p. 51).

Lindsay: Bem, isso porque não é tão fácil para a maioria das mulheres separar amor e sexo como os homens fazem.

Melanie: Sim. Isso foi sempre o que me incomodou nos homens, especialmente em se tratando da sua primeira vez.

Lindsay: Quero dizer, ali você está permitindo que alguém entre em seu corpo. Melanie: Digo, você nunca esteve tão perto de alguém em toda a sua vida.

Lindsay: E antes que você se dê conta, você está apaixonado por essa pessoa, que a faz sentir de uma forma que você nunca tinha sentido antes.

Melanie: Então você entende porque Daphne deve estar apaixonada por você.

Analisando, inicialmente, o casal masculino, verificamos a partir da fala da personagem Michael, que há um pensamento de exclusão, na questão dos encontros homossexuais masculinos, a simbologia do termo 'encontro', na fala, parece estar associada somente ao ambiente heterossexual, como se não houvesse a possibilidade de se estabelecerem encontros entre homossexuais masculinos. Além disso, a questão do sexo é bastante enfática no diálogo, pelo fato de não se ter uma representação significativa para os casais homo-masculinos, tampouco para os casais homo-femininos ${ }^{25}$. Nesse sentido, os gays seriam capazes de separar amor e sexo e, portanto, de desfrutar de sexo casual sem envolvimento emocional (NUNAN Apud ALMEIDA NETO, 1990).

No caso das lésbicas, apesar de se falar em amor e sexo, a maneira de pensar do casal homo-feminino deixa claro que há uma separação entre tais termos, onde o primeiro, está ligado à afetividade, ao carinho, e o segundo, ao prazer sexual, à libido. Nesse sentido, o amor está ligado às relações de caráter fixo, que já estão firmadas, que envolvem compromisso, e, o sexo está ligado ao prazer e não se configura como construtor de uma relação ${ }^{26}$.

Diante dessa problemática, Heilborn (2004) tece considerações significativas:

(...) a maior parte do problemas ligados à condição homossexual é este corte entre afetividade e sexualidade resultante da ausência de instituições familiares que cimentam as relações heterossexuais. Prolongando-se muito raramente mais do que alguns meses ou poucos anos, a relação do casal é frequentemente tomada hipotética desde o começo por dramas, angústias e
Observamos que mesmo entre casais homomasculinos e homo-femininos, existem relações de poder que permeiam o binarismo homem / mulher e mantém representações tradicionais e arraigadas socialmente, tais relações têm como base direcionamentos hierárquicos, traduzidos geralmente por percepções heterossexuais.

Concernente ao sexo, como foi mostrado anteriormente, há uma regulação, por parte de leis, que configuram o poder. O que significa, em primeiro lugar, que o sexo fica reduzido, por ele, a regime binário: lícito e ilícito, permitido e proibido (FOUCAULT, 1988, p. 93).

Vale ressaltar, que as relações homoconjugais masculinas e femininas não se restringem ao caráter puramente sexual. Devemos mencionar aqui, as relações estabelecidas no cotidiano, para isso, utilizaremos alguns diálogos presentes em episódios da primeira temporada.

No diálogo a seguir, Melanie e Lindsay levam o filho (Gus) ao hospital, pois ele está doente:

Enfermeiro: Quais são os sintomas?

Melanie: Diarreia, vômito, febre.

Enfermeiro: Sabe a temperatura?

Lindsay: Quase $40^{\circ}$.

Melanie: Nós nos preocupamos com desidratação.

Enfermeiro: Vamos checar. Quem é a mãe?

Lindsay: Sou a mãe biológica.

Enfermeiro: Venha comigo! Você espera aqui (para a Melanie).

Lindsay: Nós somos um casal.

Enfermeiro: Neste caso, tem os papéis da adoção?

Lindsay: Adoção?

Melanie: Ainda não planejamos.

Enfermeiro: Só os guardiões legais podem entrar.

Melanie: Pare de falar e leve-o agora.

Lindsay: Volto quando souber algo.

Melanie: Amo você. (Ela vai falar com a recepcionista). Com licença, preciso ir lá dentro. Minha parceira esqueceu a manta e não quero o bebê...

Recepcionista: Senhorita, ,ou seja, lá o que for... já foi explicado que só os pais ou guardiões legais podem acompanhar o bebê.

Melanie: Acredito que deve ser explicado a você que sou eu quem o ama, alimenta, troca, limpa sua sujeira, paga as contas e

Ramon Pereira dos Reis 
ouça aqui! (Ela tinha baixado a cabeça $e$ não olhava para Melanie). Passo a noite acordada preocupada com que ele cresça, seja feliz e amado e não ouse dizer que não tenho o direito de estar com ele (Brian chega nesse momento).

Brian: $O$ que está havendo?

Melanie: Não me deixaram entrar lá.

Brian: Por quê?

Melanie: Não sou guardiã, estou enlouquecendo.

Brian: É a maldita burocracia? (o enfermeiro chega).

Melanie: Com licença, este é o pai.

Enfermeiro: Eu o levo até lá.

Brian: Ela também vai.

Melanie: Não se preocupe, vá e dê isso a ele (a manta).

No diálogo a seguir, no bar, Ted, Emmett e Brian, conversam com Michael sobre o fato de ele ter um namorado:

Ted: Se anda com um namorado e fala como um namorado.

Ted/Emmett: Só pode ser um namorado.

Brian: Dá pra calarem a boca? É ótimo Mike ter um caso mais sério.

Michael: Não é nada sério, só saímos duas vezes.

Ted: Consideramos isso um relacionamento.

Emmett: Logo estarão trocando alianças.

Ted: Numa cerimônia onde 200 convidados já transaram com um ou dois pombinhos.

Emmett: Nos prometa que não vão usar ternos brancos iguais.

Michael: Isso nunca vai acontecer!

Emmett: Então é bom tomar cuidado com os sinais.

Michael: Que sinais?

Ted: Como quando ele lhe dá flores.

Emmett: Ou convida-o para passar o fim de semana nas montanhas.

Ted: Onde só verá o teto do quarto.

Emmett: E o aviso mais importante: quando ele conhece sua mãe e ela o convida para jantar.

No primeiro diálogo, fica evidente, apesar do cuidado, do amor, da atenção dada ao filho, naquela sociedade o preconceito é muito forte, o qual esbarra na questão da adoção. Torna-se latente no diálogo o fato das legislações não assegurarem direitos civis semelhantes aos estipulados a casais heterossexuais: direito à herança, partilha de bens, declaração conjunta de renda, adoção, dentre outros. ${ }^{27}$

No segundo diálogo, os amigos de Michael conversam com ele sobre relacionamentos: $\mathrm{O}$ que se pode considerar como um relacionamento sério? Nessa economia dos sentimentos, existem sinais que indicam quando se está namorando ou não? A questão da construção dos relacionamentos homoconjugais masculinos é muito presente, praticamente em todo o seriado, pelo que observamos, ao longo da primeira temporada, os amigos Ted, Emmett, Michael, Brian nunca experimentaram relacionamentos de longa duração ${ }^{28}$ e apenas estabeleceram vínculos muito rápidos. Esta realmente parece ser a tônica dos relacionamentos e, os sujeitos estão bastante avisados a respeito da instabilidade e do não-lugar ${ }^{29}$ sobre o qual se assenta o vínculo de amor mantido por eles (PAIVA, 2007, p. 271).

Constantemente, temos visto que existe certa necessidade tanto dos gays quanto das lésbicas, do seriado, em tentar buscar um modelo de relacionamentos, no qual seja possível se basear construir e / ou estabelecer parcerias e, além disso, para que sejam reconhecidos pela sociedade. Assim, na ausência de validação social, legal e religiosa, assim como na falta de modelos de relacionamentos nos quais possam se espelhar, com frequência, eles criam suas próprias normas conjugais (NUNAN Apud SIMON, 1996).

\section{Diálogos com a Pesquisa de Campo}

A pesquisa de campo, propriamente dita, foi elaborada através da coleta de dados empíricos, a partir de entrevistas semi-estruturadas com telespectadores da primeira temporada do seriado. Foi aplicado um questionário ${ }^{30}$ com 25 perguntas para um total de 10 interlocutores ( 5 homens e 5 mulheres), ${ }^{31}$ na faixa etária entre 18 a 28 anos, onde a maioria está cursando o ensino superior. Vale lembrar, que os nomes dos informantes foram trocados propositalmente, pelos nomes dos personagens principais, a fim de preservar a identidade de cada interlocutor.

Segue abaixo, uma tabela de dados (quadro 1) que facilitará a visualização e compreensão dos perfis dos interlocutores:

Tecendo considerações a respeito da tabela, além de termos o perfil de cada informante, percebemos, a partir das respostas, como eles encaram e se posicionam dentro do contexto ao qual estão inseridos.

Falar sobre orientação sexual, identidade de gênero e identidade sexual, num primeiro momento, talvez

\section{Ramon Pereira dos Reis}


Tabela de dados

(Quadro 1)

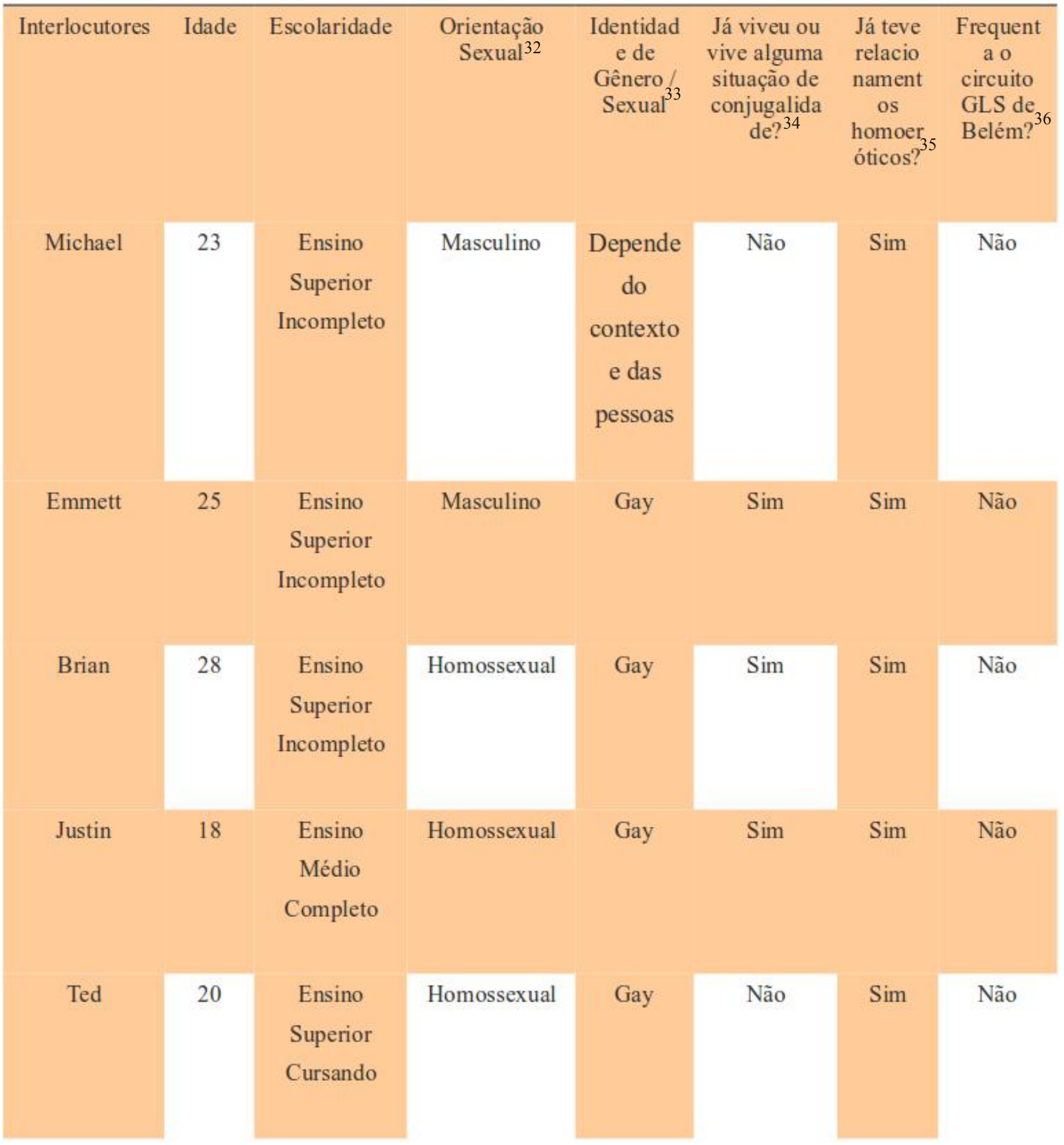

Ramon Pereira dos Reis 
Lésbicas = 'Afeto' / Gays= 'sexo'? : Discutindo

Práticas Homoconjugais no Seriado 'Queer as Folk'

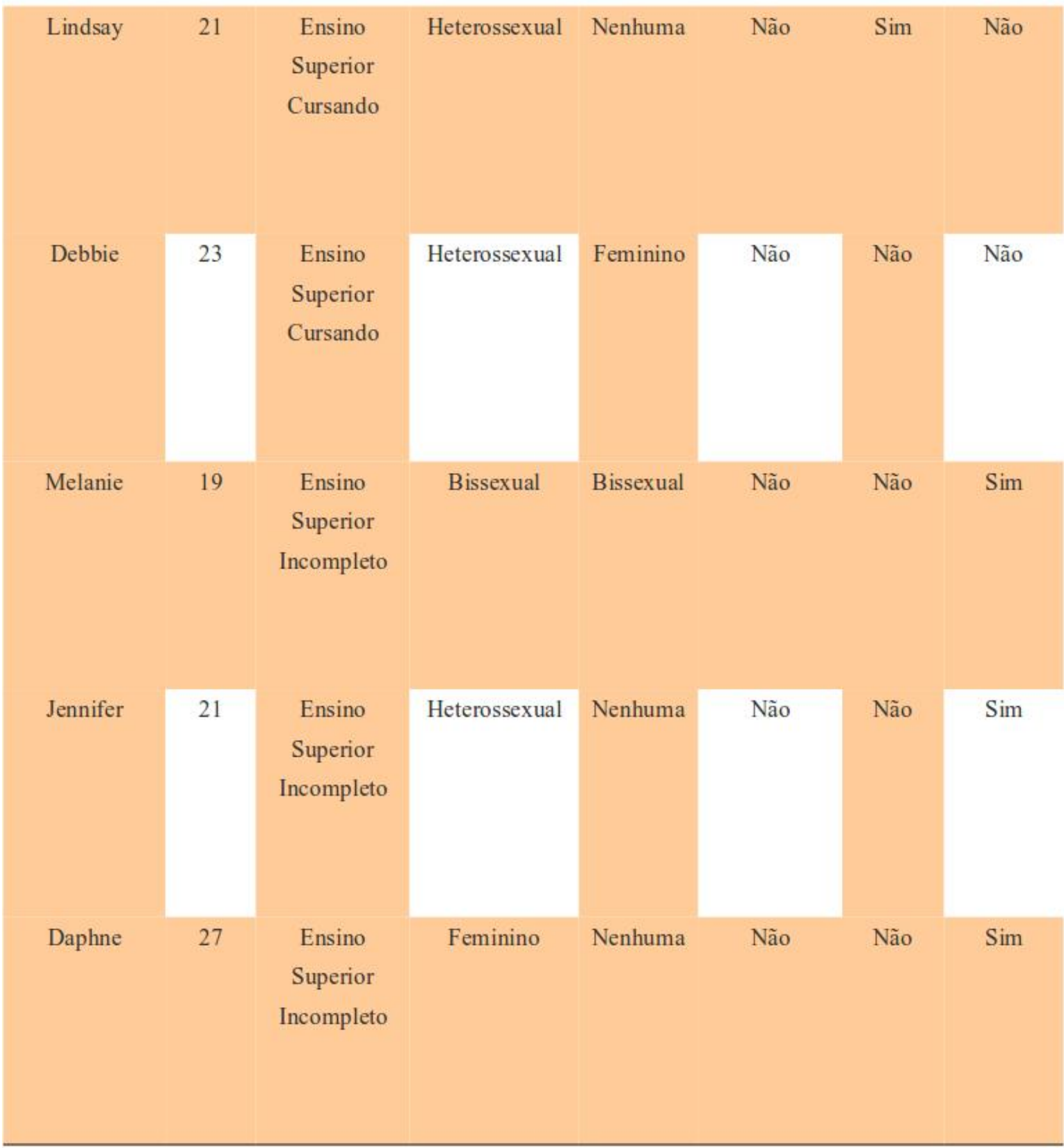

Fonte: Pesquisa de Campo, 2009.

Ramon Pereira dos Reis 
sejam questões complicadas, pois parecem muito próximas e parecidas, mas numa análise mais aprofundada veremos que se constituem enquanto importantes categorias de análise, dizendo respeito a um discurso identificatório; é como alguém se posiciona em meio à sociedade; é a maneira como eu quero que as pessoas me reconheçam.

De maneira simples, falar de orientação sexual é considerar a homossexualidade (atração física e emocional por indivíduos do 'mesmo sexo'); a heterossexualidade (atração física e emocional por indivíduos do 'sexo oposto'); e a bissexualidade (atração física e emocional tanto por indivíduos do 'mesmo sexo' quanto pelo 'sexo oposto'), nesse sentido, responder que determinada orientação sexual é masculina ou feminina, tal como, alguns informantes responderam, não cabe, pois falar de masculino e feminino é referir-se ao gênero e, este é muito mais do que falar de características sexuais, isso:

(...) remite a los diferentes contenidos socioculturales que se dan a esas características biofisiológicas entre hombres y mujeres estableciendo comportamientos, actítudes y sentimientos masculinos y femininos y jerarquizándolos de modo que se da mayor valor para los que se identífican com lo masculino (SÁNCHEZ; GALÁN, 2006, p. 146).

Do mesmo modo, quando falamos em identidade de gênero (masculino e feminino) e identidade sexual (travesti, transexual, gay, lésbica, bissexual, etc.), acontecem algumas confusões, alguns autores preferem trabalhar somente com uma categoria, outros não gostam de trabalhar com o termo identidade, por entenderem que, este, delimita o sujeito e engaveta-o numa determinada classificação, preferindo trabalhar com o termo performance ${ }^{37}$, entendido como algo transitável e maleável. O que podemos dizer é que tais categorias dizem muito dos discursos de afirmação que cada um dos informantes traz consigo: as maneiras como eles se identificam, se sentem, se apresentam para si e para os demais, as práticas, os desejos, os pensamentos, tudo isso visualizado através de um contexto sociocultural.

A seguir, mostrarei quatro entrevistas (2 homens e 2 mulheres), referentes à $17^{\mathrm{a}}$ pergunta. ${ }^{38}$ :

Bom, eu acho que aí é... já vai mais parte do ser humano, né?! É a questão de tentar se compreender... tentar... eles tentam sempre buscar, né?! A relação perfeita e, pra isso vai passando, vai conhecendo e, à noite saindo... e aí uma relação dá certo, depois não dá mais, e é isso que o seriado tenta mostrar, que é interessante, também, como eles mostram, né?! Essa procura, essa busca, o fato de, às vezes, eles descobrirem de uma amizade, mesmo, que pode ser algo mais, pode ter um significado maior $e$ acredito que seja isso (Jennifer, 21 anos, sexo feminino, orientação sexual heterossexual, não se atribui identidade de gênero / sexual, ensino superior incompleto, entrevista em 15 de agosto de 2009, Belém, Pará).

Eu acho que não existe muito a diferença entre homens e mulheres encarar a relação conjugal. Em todos, e não só os homens, o que existe é uma diferença, mesmo, cultural, de educação, entre homem e mulher. $O$ homem, ele foi educado, quando criança, que não tem aquela coisa: 'Ah! Ele é gay, ele é homo, ele é isso, ele é aquilo outro, ou ela é isso, ela é aquilo outro... é aquela coisa: mulher é educada pra se preservar, pra cuidar, pra manter relações estáveis, o homem é educado pra caçar, pra pegar, pra ficar com todo mundo, então existe a relação, aí, nessa base, mas a partir do momento que ser adulto, independente da identidade sexual que assume, acho que todos querem a mesma coisa (Daphne, 27 anos, sexo feminino, orientação sexual feminina [heterossexual], não se atribui identidade de gênero / sexual, ensino superior incompleto, entrevista em 10 de junho de 2009, Belém, Pará).

Eu acho que vai da cabeça de cada um. Tem uns lá que têm uma ideia bem romântica, como o Michael, né?! Ele já... é Michael, né?! [risos]. O Michael, ele tem uma ideia bem romântica, assim... tal... os dois juntos, mesmo, e tem outras pessoas que... ali na série, que já não tem essa ideia, não idealizam uma pessoa, não imaginam um relacionamento só os dois juntos, é igual vida real, mesmo, né?! (Brian, 28 anos, sexo masculino, orientação sexual homossexual, identidade de gênero / sexual gay, ensino superior completo, entrevista em 20 de junho de 2009, Belém, Pará).

É como eu falei naquela hora, também, sobre os meus amigos aqui, os homens

\section{Ramon Pereira dos Reis}


curtir, curtir, curtir, e as mulheres ficar $e$ construir algo, tanto é que os personagens mais experientes que nós temos, todos eles estão solteiros, eles podem estar buscando, mas o que fica claro ali é que eles estão buscando o quê? Eles estão buscando alguém pra aquela hora, pra depois não. $O$ seriado já começa com as lésbicas casadas, elas já moram juntas, tanto é que no início, uma delas tem o filho e, o filho é pra duas, então essas relações que são colocadas ali, de homens e mulheres, perpassa muito por essa questão de, querendo ou não, fazendo essa associação, se é certo ou errado, não sei quem a cabe julgar. Mas, o homem, mesmo, gay, ele ainda tem aqueles traços machistas: de pegar, de ficar, de ter o outro, e a mulher ainda é aquela coisa de: estar na casa, construir algo, ficar, ter relacionamento, ter as nossas coisas junto, então só muda o gosto, o hétero que fica lá com a mulher, mas ele fica com uma agora e fica com outra depois, o homossexual lá, que fica com outro homem, mesma coisa! Ele fica com um aqui, fica com outro ali, fica com outro que ele quer ficar, o que ele quer é manter as relações sexuais dele e, com a mulher já é mais diferente (Michael, 23 anos, sexo masculino, orientação sexual masculina [heterossexual], a identidade de gênero / sexual depende do contexto e das pessoas, ensino superior incompleto, entrevista em 06 de junho de 2009, Belém, Pará).

Inicialmente, falar das representações midiáticas de casais gays e lésbicos é, muito mais, do que apenas veicular informações:

(...) a mídia também produz saberes, formas específicas de comunicar o que é masculino e feminino. As maneiras como são valorados os gêneros implicam manutenção ou subversão de comportamentos, sentimentos e interdições que ajudam a moldar a vida de homens e mulheres (BORGES, 2007, p. $370)$.

Dentro desse viés midiático de representação, existe, muito mais, uma questão cultural do que um determinismo biológico, pois antes de falarmos de gays e de lésbicas, que são consideradas identidades sexuais, há um registro sexual no momento do nosso nascimento, dizendo que seremos homens ou mulheres e que devemos nos comportar e atuar, na sociedade, por meio de condutas preestabelecidas

Tal produto midiático, transmite uma lógica identitária de pensamento e, alguns informantes, por exemplo, Michael, se apropria dessas ideias e as transmite num discurso relacional com o machismo e com características que devem estar intimamente ligadas ao gênero masculino e ao gênero feminino, no caso de colocar o homem sempre em uma posição de superior e a mulher sempre numa condição de inferior e, além disso, associar o gênero feminino aos relacionamentos mais estáveis e o gênero masculino, aos relacionamentos mais voláteis.

Por outro lado, de acordo com a fala da informante Daphne, o que prevalece não são diferenças entre como os gays e lésbicas encaram as relações homoconjugais, 'o que existe é uma diferença, mesmo, cultural, de educação'. Os gêneros:

(...) "masculino" e o "feminino" são criações culturais e, como tal são comportamentos apreendidos através do processo de socialização que condiciona diferentemente os sexos para cumprirem funções sociais específicas e diversas. Essa aprendizagem é um processo social. Aprendemos a ser homens e mulheres e a aceitar como "natural" as relações de poder entre os sexos. A menina, assim, aprende a ser doce, obediente, passiva, altruísta, dependente; enquanto o menino aprende a ser agressivo, ativo, independente (ZANFORLIN Apud ALVES E PITANGUY, 1991, p. 55-56).

\section{Considerações Finais}

No final das contas, todos (gays e lésbicas) querem a mesma coisa, seja com uma ideia romântica ${ }^{39}$ de relacionamento ou não, como assinala o informante Brian, ou seja, os casais homoconjugais, nesse sentido, querem estabelecer relações. Mas que tipo de relação? Foucault (1988) ressaltou que o personagem homossexual do século XIX está alocado numa região das sexualidades periféricas e, dessa forma, utilizandose dos dispositivos de saturação sexual, que dizem respeito ao espaço e aos ritos sociais do século XIX, podemos dizer que a sociedade moderna procurou reduzir a sexualidade ao casal - ao casal heterossexual, numa possibilidade de relação legítima.

O sentido da busca de uma relação, por vezes 'perfeita', como menciona a informante Jennifer, extrapola binarismos (masculino / feminino; superior / inferior; certo / errado; lícito / ilícito; legítimo /

\section{Ramon Pereira dos Reis}


ilegítimo) e vai à busca da compreensão de como o ser humano se comporta: quais as atitudes que cada um toma pra si, no sentido de não generalizarmos tanto a conduta das personagens quanto daqueles que não fazem parte da ficção.

Tecendo considerações finais, trago à tona a seguinte questão: Até que ponto é possível considerarmos que as categorias identitárias dos papéis sexuais / sociais masculinos e femininos interferem na construção e / ou no estabelecimento de relações homoconjugais?

Vimos que a lógica das construções homoconjugais não parte do fato de sermos gays ou lésbicas, e sim dos processos de socialização apreendidos pela cultura, indicando o que é ser homem e o que é ser mulher. Além disso, devemos destacar que a condição de classe dos sujeitos também influencia. O seu status social e o fato de pertencerem às camadas médias as aproximam de certos valores de igualitarismo, educação para a fidelidade e relacionamentos simétricos. A cultura foi mostrada, ao longo deste capítulo, como componente fundamental ao entendimento das relações homoconjugais expostas no seriado QAF, mas será que, somente dizer que são construções convencionais de gênero basta? Será que não existiria certa propensão do ser humano em querer estabelecer relações conjugais estáveis ou não-estáveis com as / os parceiros / as, visto que, não podemos generalizar e dizer que todos os homossexuais se comportam da mesma forma? Essas questões não podem e nem devem ser esgotadas aqui, muito ainda, deve ser comentado sobre isso e, serve, também, de reflexão ao leitor.

$1 \quad$ O nome do seriado é uma brincadeira com um ditado inglês, de "ninguém é tão estranho como nós" ("nobody is so weird as folk"), para "ninguém é tão gay como nós" ("nobody is so queer as folk"). No Brasil, o seriado foi exibido com o título "Os assumidos".

2 A proposta dos produtores é falar de pessoas tão comuns como outras quaisquer, que poderiam "viver na porta ao lado" sem apelar para símbolos comuns à imagem do gay. Sem estigmas, de gestos, roupas, modos de falar rompendo com a "virtualidade" da prática homossexual (ZANFORLIN, 2005, p. 60).

A cidade foi considerada um paralelo de Manchester, uma típica "working-class city" na acepção dos produtores, como comenta Lipman: "Sentimos que era muito importante que se passasse numa típica cidade de classe média americana como Pittsburgh. Quisemos que se tratasse mais sobre pessoas que podemos encontrar na porta ao lado"
(ZANFORLIN, 2005, p. 60).

4 Houve mudanças nos nomes das personagens, sem alteração da essência, ou seja, mantiveram-se profissões, laços familiares, como toda a trama narrativa, sendo esta modificada a partir do $14^{\circ}$ episódio (ZANFORLIN, 2005, p. 60).

5 A versão inglesa continha 13 episódios, e foi cancelada por causa de divergências sobre o valor dos cachês entre o produtor e os atores (ZANFORLIN, 2005, p. 59).

6 O canal Showtime gastou 10 milhões de dólares em campanhas publicitárias, e conseguiu fazer de Queer as Folk a série com maiores índices de audiência do canal em três anos, com um público que variava dos 18 aos 35 anos (ZANFORLIN, 2005, p. 60)

7 A sigla foi utilizada tendo como referência o trabalho de Marina Fisher Nucci (UERJ); Ana Paula Lopes de Melo (UERJ) e Marcos Castro Carvalho (UERJ): Conjugalidades homossexuais nos seriados televisivos Queer as Folk e The L Word: onde gênero e sexualidade se cruzam, apresentado no Fazendo Gênero 8 - Corpo, Violência e Poder, em Florianópolis, de 25 a 28 de Agosto de 2008.

8 Se a ideia norte-americana de friendly referese a espaços frequentados predominantemente por heterossexuais, nos quais homossexuais são bem vindos, a ideia brasileira de GLS segue o caminho inverso: o S da sigla indica "simpatizante", tendo como ponto de partida espaços frequentados majoritariamente por homossexuais e revelando uma intenção de expandir as fronteiras do "gueto", quando propõe abarcar também consumidores que não se identificam como homossexuais, mas que de alguma forma participam desse universo (FRANÇA, 2007)

9 (...) a própria sociedade, em geral, significa a interação entre indivíduos. Essa interação surge sempre a partir de determinados impulsos ou da busca de certas finalidades. Instintos eróticos, interesses, objetivos, impulsos religiosos, objetivos de defesa, ataque, jogo, conquista, ajuda, doutrinação e inúmeros outros fazem com que o ser humano entre, com os outros, em uma relação de convívio, de atuação com referência ao outro, com o outro e contra o outro, em um estado de correlação com os outros. Isso quer dizer que ele exerce efeitos sobre os demais e também sofre efeitos por parte deles. Essas interações significam que os portadores individuais daqueles impulsos e finalidades formam uma unidade - mais exatamente, uma "sociedade" (SIMMEL, 2006, p. 59-60).

10 Tradução minha.

11 Quando trabalhamos com a sigla LGBT estamos nos referindo a uma comunidade, uma espécie de grupo que luta por direitos igualitários para

\section{Ramon Pereira dos Reis}


Lésbicas, Gays, Bissexuais, Travestis e Transexuais. LGBT seria uma categoria política, diferente de GLS que está muito mais ligado ao consumo.

12 O que diferencia Os Assumidos de outros seriados que possuem entre suas personagens homossexuais é uma nova disposição em relação à forma de representá-los. Primeiro, o seriado foi pensado para o público gay, para levar para as telas de veículo massivo, a televisão, o estilo de vida e as relações vivenciadas no cotidiano, que envolvem família, trabalho, doenças, relacionamentos amorosos, etc. (ZANFORLIN, 2005, p. 60-61).

$13 \mathrm{O}$ trabalho de Ângela Cristina S. Marques, apresentado no XXV Congresso Brasileiro de Ciências da Comunicação - Salvador/BA - 1 a 5 de Setembro de 2002, com o tema: Da Esfera Cultural à Esfera Política: a representação da homossexualidade nas telenovelas e a busca por reconhecimento, é significante para o entendimento relacional com o seriado, pois ela diz que, quando questões polêmicas, como a homossexualidade, é abordada, por gêneros midiáticos específicos, como a telenovela, elas ganham uma dimensão de visibilidade capaz de instaurar um debate público que convoca indivíduos e grupos a se posicionarem diante de tais questões. Reflexivamente, esses indivíduos e grupos formulam ideias e posturas capazes de pôr em movimento discursos que, ao se encontrarem com a fala dos "outros", conferem uma nova dinâmica as relações de sociabilidade e estimulam a reconfiguração das identidades individuais e coletivas.

14 Os espaços de convivência entre homens e mulheres são distintos, por exemplo: gays sempre aparecem na boate, no bar, na sauna, na rua, flertando, transando, reunidos entre amigos, enquanto que, quando aparece o único casal de lésbicas, elas estão sempre em casa, quase não saem, não aparecem flertando, sempre estão discutindo a relação, o universo delas se restringe ao trabalho e a casa (REIS, 2010).

15 Ver LOURO, Guacira Lopes. Um corpo estranho - ensaios sobre sexualidade e teoria queer, Belo Horizonte: Autêntica, 2004.

16 Ver Idem.

17 "Queer" pode funcionar como substantivo, adjetivo ou verbo, mas em qualquer caso se define contra o "normal" ou normatizador. A teoria queer não é um quadro de referência singular, conceitual ou sistemático, mas sim uma coleção de compromissos intelectuais com as relações entre sexo, gênero e desejo sexual. Se a teoria queer é uma escola de pensamento, então ela é uma escola com uma visão bastante heterodoxa de disciplina. O termo descreve um leque diverso de práticas e prioridades críticas; leituras da representação do desejo pelo mesmo sexo em textos literários, filmes, músicas e imagens; análise das relações de poder sociais e políticas da sexualidade; críticas do sistema sexo-gênero; estudos de identificação transsexual e transgênero, de sadomasoquismo e de desejos transgressivos (SPARGO, 2006, p. 8-9).

18 A superioridade social do "ativo" sobre o "passivo" é nitidamente expressa nas palavras de gíria que usamos para falar das relações sexuais como: "comer" e "dar", "ficar" por "cima" e "abrir as pernas". Quem "come", vence, como um jogador de xadrez que tira as peças de seu adversário do tabuleiro, "comendo-as". Quem "come" está "por cima" e quem está por cima é quem controla. Quem "dá" ou quem "abre as pernas" é quem se rende totalmente (FRY \& MACRAE, 1991, p.48).

19 A declaração 'É uma menina!' ou 'É um menino!' também começa como uma espécie de 'viagem', ou melhor, instala um processo que, supostamente, deve seguir um determinado rumo ou direção. A afirmativa, mais do que uma descrição, pode ser compreendida como uma definição ou decisão sobre um corpo [...] Um processo que é baseado em características físicas que são vistas como diferenças e às quais se atribui significados culturais. Afirma-se e reitera-se uma sequência de muitos modos já consagrada, a sequência sexo-gênero-sexualidade. $\mathrm{O}$ ato de nomear o corpo acontece no interior da lógica que supõe o sexo como um "dado" anterior à cultura e lhe atribui um caráter imutável, a-histórico e binário (LOURO, 2004, p.15).

20 A utilização das aspas nas palavras: pai, dependente, ativo e passivo, faz-se necessário, pois entendemos que são representações sociais, por esse motivo não se pautam a partir de uma lógica determinista e / ou generalizante.

21 A gramática da cópula também pode ser traduzida para o termo economia das relações amorosas (passivo / ativo) utilizado por Paiva (2007), mais acessível ao entendimento.

22 Tal termo pretende ser um descritor de contatos sexuais entre homens e mulheres e sem que haja a centralidade da sexualidade, que é uma figura por demais histórica. (HEILBORN, 2004, p.15)

23 É pela maternidade que a mulher realiza integralmente seu destino fisiológico; é a maternidade sua vocação "natural", porquanto todo o seu organismo se acha voltado para perpetuação da espécie (ZANFORLIN Apud BEAUVOIR, 1980, p.248).

24 Ao mencionar o termo construção estereotípica, procuro estabelecer relação com o que Goffman (2008) diz sobre estigma, no qual está ligado com a nossa rotina de relações sociais diárias com

\section{Ramon Pereira dos Reis}


"outras pessoas" previstas sem atenção ou reflexão particular... O termo estigma, portanto, será usado em referência a um atributo profundamente depreciativo, mas o que é preciso, na realidade, é uma linguagem de relações e não de atributos. Um atributo que estigmatiza alguém pode confirmar a normalidade de outrem, portanto ele não é, em si mesmo, nem honroso nem desonroso (GOFFMAN, 2008, p. 12-13).

25 (...) quando irrompe nos mapas da simbólica sexual binária (homem / mulher), a homossexualidade é alojada no território do marginal, do desvio, do estrangeiro (PAIVA, 2007, p. 247).

26 Sob os auspícios do amor, o lesbianismo grafa de forma exagerada os limites de sua traduzibilidade e revela que sua artimanha é justamente dialogar com o pensamento, lá onde consideramos domínio oposto à razão, a saber, a afetividade, que no "amor entre mulheres" é levada às últimas consequências (HEILBORN Apud MUNIZ, 1989, p.49-50).

27 Do mesmo modo, a falta de rituais que marquem a união, assim como a inexistência do direito de casar-se legalmente exclui estes casais de validação social e legal. Dito de outra forma, para casais homossexuais resta a confusão que os membros da família de origem experienciam no processo de tentar entender seus papéis com relação ao novo casal. A ausência de uma festa de casamento ou de uma cerimônia equivalente tende a confirmar o estigma com relação aos homossexuais, perpetuando a crença de que estes casais devem ser mantidos em segredo (NUNAN, 2007, p.49).

28 Para identificar relacionamentos homoconjugais longos e estáveis utilizo a variação que Paiva (2007) utilizou na sua pesquisa de doutorado de 3 a 21 anos.

29 A partir dos estudos antropológicos, podemos dizer que a união homossexual apresenta-se como o estado zero das relações sociais, como não-relação (PAIVAApud BALANDIER, 1976, p.41).

30 O questionário aplicado possui quatro momentos: um primeiro momento, no qual podemos visualizar um pequeno perfil de cada interlocutor; em seguida, focalizamos em perguntas específicas sobre o seriado; no terceiro momento perguntávamos sobre conjugalidade homossexual, mesclando com questões sobre QAF; por fim, trouxemos à tona questões mais atuais que dizem respeito à como a homoconjugalidade é vista / percebida / encarada pela sociedade brasileira / paraense.

31 Vale ressaltar que, no momento das entrevistas, não direcionamos nossa pesquisa, apenas, à comunidade LGBT, ou seja, nossa intenção não era entrevistar somente gays e lésbicas, mas sim, aquelas pessoas que assistiram a primeira temporada do seriado.

32 O termo orientação sexual foi utilizado por referir-se ao sexo das pessoas que elegemos como objetos de desejo e afeto. Hoje são reconhecidos três tipos de orientação sexual: a heterossexualidade (atração física e emocional pelo "sexo oposto"); a homossexualidade (atração física e emocional pelo "mesmo sexo"); e a bissexualidade (atração física e emocional tanto pelo "mesmo sexo" quanto pelo "sexo oposto") (Gênero e Diversidade na Escola, 2009, p. 7).

33 A partir das respostas dos informantes, percebemos que não estamos trabalhando apenas com a categoria identidade de gênero (performance), assim como, com identidade sexual, pois ao falarmos de identidade de gênero nos referimos à maneira como alguém se sente, se identifica, se apresenta para si e para os demais e como é percebido / a como "masculino" ou "feminino" ou, ainda, uma mescla de ambos independente tanto do sexo biológico quanto da orientação sexual (Gênero e Diversidade na Escola, 2009 , p. 7). No caso da identidade sexual: al igual que ocorre com el gênero respecto al sexo, determinadas sexualidades (es decir, sentimientos, prácticas, deseos, pensamientos...) se marcan culturalmente y devienem em identidades. Así, surgen identidades sexuales basadas en el sexo de las personas que participan en las mismas como: homosexualidad, heterosexualidad y bisexualidad. Pero las identidades basadas em La sexualidad acaban siendo mucho más amplias y complejas: gay, lesbiana, queer, sadomasoquista, asexual, dominatrix... (SÁNCHEZ; GALÁN Org, 2006, p. 143-156).

34 O termo conjugalidade é baseado naquilo que Heilborn (2004) fala, dizendo respeito a modalidades de arranjo cotidiano, nesse sentido levamos em conta o namoro como possível formato de conjugalidade e, não resumimos este ao aspecto coabitacional.

35 A intenção da pergunta foi de tentar identificar se o informante já teve algum contato homocorporal, o que não se resume apenas ao ato sexual, podendo, também, serem consideradas as relações de afeto e carinho.

36 Tal como na pergunta anterior, a intenção foi de perceber se, algum dos informantes, já tiveram contato com o circuito GLS de Belém, pois este, não se resume somente a boates, mas também a mostras de filmes, paradas da diversidade sexual, saunas, bares, etc.

37 BUTLER, Judith. Problemas de Gênero: feminismo e subversão da identidade. Rio de Janeiro: Civilização Brasileira, 2004.

38 Como você percebe, no seriado, que gays e

\section{Ramon Pereira dos Reis}


lésbicas encaram as relações homoconjugais?

39 A ideia de um relacionamento romântico se configura a partir do entendimento de um amor romântico, estruturado pela afeição e tido como o motivador do "casamento" contemporâneo, o qual focaliza a procura de um ser insubstituível e único (HEILBORN, 2004).

\section{Referências}

BORGES, Lenise Santana. "Lesbianidade na TV: visibilidade e 'apagamento' em telenovelas brasileiras. In: GROSSI, Mirian Pillar; UZIEL, Ana Paula; MELLO, Luiz (Orgs.) Conjugalidades, parentalidades e identidades lésbicas, gays e travestis, Rio de Janeiro: Garamond, 2007, p. 363379 ;

BUTLER, Judith. Problemas de gênero: feminismo e subversão da identidade. Rio de Janeiro: Civilização Brasileira, 2003;

DAMATTA, Roberto. A casa \& a rua. $5^{\text {a }}$ ed, Rio de Janeiro: Rocco, 1997, p. 11-63;

FOUCAULT, Michel. Michel Foucault, an Interview: Sex, Power and the Polites of Identity; entrevista com B. Gallagher e A. Wilson, Toronto, junho de 1982; The Advocate, n. 400, p. 26-30 e 58, 7 de agosto de 1984 .

História da sexualidade I: A vontade de saber. Rio de Janeiro: Graal, 1988.

FRANÇA, Isadora Lins. Sobre 'guetos' e 'rótulos': tensões no mercado GLS na cidade de São Paulo. Cadernos Pagu, nº. 28, p. 227 - 255, jan/jun 2007.

FRY, Peter; ;MACRAE, Edward. O que é homossexualidade. $7^{\text {a }}$ ed., São Paulo: Brasiliense, 1991.

Gênero e Diversidade na Escola: Formação de Professoras/es em Gênero, Orientação Sexual e Relações Étnico-raciais. Livro de Conteúdo. Versão 2009. - Rio de Janeiro: CEPESC; Brasília: SPM, 2009;

GOFFMAN, Erving. Estigma: Notas sobre a manipulação da identidade deteriorada. $4^{\mathrm{a}} \mathrm{Ed}$, Rio de Janeiro: Guanabara Koogan S.A, 2008, p. 137-158.

HALL, Stuart. A identidade cultural na pósmodernidade. $11^{\mathrm{a}}$ ed., Rio de Janeiro: DP \& A, 2006.
HEILBORN, Maria Luiza. Dois é par: Gênero e identidade sexual em contexto igualitário. Rio de Janeiro: Garamond, 2004.

LOURO, Guacira Lopes. Um corpo estranho ensaios sobre sexualidade e teoria queer. Belo Horizonte: Autêntica, 2004.

MARQUES, Ângela Cristina S. Da Esfera Cultural à Esfera Política: a representação da homossexualidade nas telenovelas e a busca por reconhecimento. In: XXV Congresso Brasileiro de Ciências da Comunicação, Salvador, BA, 1 a 5 de setembro de 2002;

NUCCI, Marina Fisher; MELO, Ana Paula Lopes de; CARVALHO, Marcos Castro. Conjugalidades homossexuais nos seriados televisivos Queer as Folk e The L. World: onde gênero e sexualidade se cruzam. In: Fazendo Gênero 8 - Corpo, Violência e Poder, Florianópolis, de 25 a 28 de agosto de 2008.

NUNAN, Adriana. Influência do preconceito internalizado na conjugalidade homossexual masculina. In: GROSSI, Mirian Pillar; UZIEL, Ana Paula; MELLO, Luiz (Orgs.) Conjugalidades, parentalidades e identidades lésbicas, gays e travestis, Rio de Janeiro. Garamond, 2007, p. 47-64.

PAIVA, Antonio Cristian S. Reservados e invisíveis: o ethos íntimo das parcerias homoeróticas. Campinas: Pontes; Fortaleza, PPG em Sociologia da UFC, 2007

REIS, Ramon Pereira dos. Conjugalidades homossexuais na mídia televisiva: o discurso midiático pautando as relações homoconjugais expostas no seriado Queer as Folk. Trabalho de Conclusão de Curso (Ciências Sociais) - Instituto de Filosofia e Ciências Humanas, Belém, Universidade Federal do Pará, 2010.

SÁNCHEZ, Ángel Moreno; GALÁN, José Ignacio. Homonormatividad y existência sexual. Amistades peligrosas entre gênero y sexualidad. Revista de Antropologia Iberoamericana, Ed. Electrónica, vol. 1, no 1, p. 143-156,Enero - Febrero, 2006.

SIMMEL, Georg. Questões fundamentais da sociologia: indivíduo e sociedade. Rio de Janeiro: Jorge Zahar, 2006, p. 59-82.

SPARGO, Tamsin. Foucault e a teoria queer. Rio de Janeiro: Pazulin, 2006. 
ZANFORLIN, Sofia. Rupturas possíveis: representação e cotidiano na Série Os Assumidos (Queer as Folk). São Paulo: Annablume, 2005.

\section{APÊNDICE A - QUESTIONÁRIO DE PERGUNTAS}

Idade:

Escolaridade:

Sexo que foi registrado ao nascer:

Orientação sexual:

Identidade de gênero / sexual:

$1^{\text {a }}$ - Onde você ficou sabendo da existência deste seriado?

$2^{\mathrm{a}}$ - Por que você resolveu assistir o seriado Queer as Folk?

$3^{\mathrm{a}}$ - O que você entende pelo termo Queer as Folk?

$4^{\mathrm{a}}$ - Quais aspectos, da $1^{\mathrm{a}}$ temporada do seriado, você destacaria?

$5^{\text {a }}$ - O que mais the chamou atenção no seriado?

$6^{\text {a }}$ - Como você considera as cenas expostas no seriado?

$7^{\mathrm{a}}$ - Você consegue fazer relação do seriado com a realidade a sua volta? Se sim, qual / quais?

$8^{\text {a }}$ - Somente para LGBT's. Você acha que o seriado retrata a realidade LGBT brasileira?

$9^{\text {a }}$ - Somente para LGBT's. Você consegue se visualizar ou visualizar algum de seus amigos em algum dos personagens principais da $1^{\mathrm{a}}$ temporada do seriado? Se sim, de que maneira?

$10^{\mathrm{a}}$ - Você tem amigos LGBT's? Se sim, você consegue relacioná-los com algum perfil dos personagens principais mostrados na $1^{\mathrm{a}}$ temporada do seriado?

11 - Quais os pontos positivos e negativos da veiculação de imagens pela mídia televisiva?

$12^{\mathrm{a}}$ - No seriado, diversas vezes se enfatiza a questão dos relacionamentos homoconjugais. Nesse sentido, o que você entende pelo termo "Conjugalidade Homossexual" ou "Homoconjugalidade"?

$13^{\mathrm{a}}$ - Para você, o que é mais intrigante quando se fala em Conjugalidade homossexual?

$14^{\mathrm{a}}$ - Você acha que há diferença (s) entre relações homoconjugais masculinas e relações homoconjugais femininas? Se sim, qual / quais?

$15^{\mathrm{a}}$ - Você acha que há distinção entre as relações homoconjugais expostas no seriado e às que você percebe no seu cotidiano? Por quê?

$16^{\mathrm{a}}$ - Dentre as situações colocadas, com relação às práticas sexuais e sociais representadas no seriado, de que maneira podem ser feitas associações com aquelas vivenciadas em nosso meio ou em nossa trajetória?

$17^{\mathrm{a}}$ - Como você percebe, no seriado, que gays e lésbicas encaram as relações homoconjugais?

$18^{\text {a }}$ - Você considera, na realidade atual, que homossexuais masculinos e homossexuais femininos querem estabelecer relações homoconjugais com os / as parceiros / as?

$19^{\text {a }}$ - Somente para LGBT's. Você consegue definir características de uma relação homoconjugal? Ela seria diferente da heterossexual em algum aspecto?

$20^{\mathrm{a}}$ - Você acha interessante a maneira como foi abordada a temática LGBT no seriado? Por quê?

$21^{\text {a }}$ - Você considera importante trabalhar a temática da conjugalidade homossexual em seriados?

$22^{\mathrm{a}}$ - O que você pensa sobre a aceitação ou não aceitação das relações homoconjugais na sociedade brasileira / paraense?

$23^{\text {a }}$ - Atualmente, você vive alguma situação de conjugalidade? Já viveu?

$24^{\mathrm{a}}$ - Você já teve relacionamentos homoeróticos?

$25^{\text {a }}$ - Você costuma frequentar o circuito GLS de Belém?

Recebido em 15 de agosto de 2010. Aceito em 10 de março de 2011.

Ramon Pereira dos Reis 